\title{
Occupational Risk of Sharp Objects or Needlestick Injuries in Medical Practice
}

\author{
A. Kircheva ${ }^{1^{*}}$, R. Konstantinov ${ }^{1}$, K. Stoyanova ${ }^{2}$ and E. Ivanova ${ }^{1}$ \\ ${ }^{1}$ Department of Hygiene and Epidemiology, Faculty of Public Health, \\ Medical University - Varna, Bulgaria \\ ${ }^{2}$ Department of Infectious Diseases, Parasitology and Dermatovenerology, \\ Faculty of Medicine, Medical University - Varna, Bulgaria \\ *Corresponding author
}

\begin{tabular}{|l|}
\hline Ke y w o r d s \\
$\begin{array}{l}\text { Sharps objects, } \\
\text { Needlestick injuries, } \\
\text { Blood-borne infections, } \\
\text { Risk exposure, } \\
\text { Occupational risk }\end{array}$ \\
\hline Article Info \\
\hline $\begin{array}{l}\text { Accepted: } \\
\text { 04 May 2018 } \\
\text { Available Online: } \\
\text { 10 June 2018 }\end{array}$ \\
\hline
\end{tabular}

\section{Introduction}

Medical practices related to constant usage of needlesticks or sharp medical instruments are dominant in present-day medicine even in some prophylactic procedures, such as

\section{A B S T R A C T}

Everyday use of sharp and cutting objects from some groups of health care workers (HCWs) presents an eminent occupational risk of exposition to blood and body fluids, potentially dangerous for transmitting blood-borne infections. Receiving an injury from sharp or cutting objects can lead to the transmission of more than 20 blood-borne pathogens. Some of them are of a particular importance to healthcare professionals due to the severe clinical course and widespread prevalence of the human immunodeficiency virus (HIV), hepatitis B virus (HBV) and hepatitis C virus (HCV). The tuberculosis infection, re-emerging in human population, can also be included with its permanent presence in the biological materials of the affected patients and the amplified pathogenicity and drug resistance. The aim of the current study is to perform an epidemiological analysis of the surveillance data on the risk taking medical procedures with elevated usage of sharp and cutting objects in one of the Multi profile Hospitals for Active Treatment (MHAT) of Varna, Bulgaria. We used the data from the official reports for "risk exposure" of the hospital's medical staff and information from additionally performed post-exposure epidemiological surveys, legislative documents of the Ministry of Health, standards and regulations of the $\mathrm{WHO}, \mathrm{CDC}$ and healthcare professional organizations. Data analysis of all affected hospital personal showed the structure of the risk exposure, the most affected professional groups and the immune status regarding blood-borne infections of both the patients and the exposed personal. Based on the summarized results we were able to define the high-risk activities leading to sharp instruments or needlestick injuries in our medical practice and the possible steps for risk reducing and prevention. 
prerequisite for transmission of many bloodborne bacterial and viral pathogens (Ridzon et al., 1997; Himmelreich et al., 2012; Wicker et al., 2008; Upjohn et al., 2012). Some of them present a noteworthy burden on the patients and on the healthcare systems due to their clinical course and pandemic distribution such as HIV/AIDS, HBV and HCV infections. Also we can add the imminent threat of tuberculosis infection, which surprises us with its new, atypical forms, qualitative changes of the causative agent and prolonged presence in the biological materials that the HCWs meet in everyday practice.

The WHO periodical reports show the extent of infectious risk for the medical staff and the human society as a whole:

Over 16 billion injections, only in developing countries and countries in transition, of which $95 \%$ - therapeutic and 3\% immunizations; (www.who.int/injection_safety/about/resources)

0, 2 up to $4,7 \%$ of all HCWs in the world suffer from work related injury each year; about 1 million needlestick incidents per year are reported only in Europe (Manchikanti et al., 2012; Europäische Agentur für Sicherheit and Gesundheitsschutz am Arbeitsplatz, 2018; Voide et al., 2012).

As a result of the risk exposure $2.6 \%$ develop $\mathrm{HCV}, 5.9 \%$ - HBV and $0.5 \%$ - HIV infection. These numbers correlate with about 16000 cases of HCV, $66000 \mathrm{HBV}$ and $1000 \mathrm{HIV}$ infected healthcare workers annually (Prüss- Üstün et al., 2005).

In the developing countries approximately 40 to $65 \%$ of $\mathrm{HCV}$ and $\mathrm{HBV}$ infections among health workers develop after percutaneous exposure (www.who.int/ injection_safety/ about/resources; Beltrami et al., 2000; Himmelreich et al., 2013).
In the everyday practice the $\mathrm{HCW}$ are at risk of diverse types of workplace exposures that are reoccurring with different frequency depending on their respective fields. The main risk factors that determine the occurrence of these accidents are: work equipment, organization of the workflow, adherence to universal precautions, the introduction of safe medical devices and of course conducting a systematic epidemiological surveillance of all risk and problematic procedures.

In Bulgaria, considering all the seriousness of the problem the necessary public attitude and legislation base were established to define the framework for safe medical procedures associated with an elevated risk of infection with blood and/or body fluids (Ministry of Health. State Gazette, 2002; Ministry of Health, 2005; Ministry of Health. State Gazette, 2013). A responsibility of regional and local medical institutions was implemented to carry out the planning and organization of the hazardous medical activities, reporting and analysing of all exposure-related medical procedures to conduct a timely post-exposure prophylaxis.

The aim of the current study is to analyse the data from the epidemiological surveillance of the risk professional activities in one of the Multi profile Hospitals for Active Treatment (MHAT) of Varna, Bulgaria that are related to the use of sharp and cutting medical devices in the context of a program-controlled hospital regulations for work in a hazardous environment.

\section{Materials and Methods}

An investigation of the following medical documents was performed:

Officially submitted Post-exposure reports of the medical staff to the MHAT's Infection control team (ICT); 
Data from the epidemiological surveys and specifically designed questionnaires of the injured or high-risk medical staff; Results of the monitoring of the methods of performing the blood manipulations and other risk procedures using sharp and cutting medical devices;

The legislation framework provided by the Ministry of Health, international standards and protocols of the WHO, CDC and professional organizations.

The study was executed by the hospital's ICT for the period between 2011 and 2016 after familiarising with the problem and providing methodological assistance to the medical specialists in the risk hospital wards. During the observation period, the ICT received 45 post-exposure reports, which were the subject of a thorough investigation and basis for the evaluation of the post-exposure behaviour.

\section{Results and Discussion}

Factual data from the Post-exposure reports and epidemiological surveys of the hospital staff:

Affected hospital wards - Emergency Unit$\mathrm{n}=12$ persons, Clinical Laboratory $-\mathrm{n}=4$, Anaesthesiology and Intensive Care Unit (AICU) - $n=4$, Surgical wards $-n=17$, Internal medicine wards $-\mathrm{n}=6$, Autoclave Unit for Treatment of Hazardous Hospital Waste (AUT-HHW) $-\mathrm{n}=3$;

Affected occupational groups (contact medical staff / CMS): physicians $-\mathrm{n}=15$, nurses $-\mathrm{n}=17$; laboratory technicians $-\mathrm{n}=4$; orderlies $-n=6$; staff of AUT-HHW $-n=3$.

Time of the risk exposure: before noon $\mathrm{n}=12$; noon $(12: 00-13: 00)-\mathrm{n}=12$; afternoon $(14: 00-17: 00)-\mathrm{n}=7$; night shift (after $19: 00)-n=14$.
Type of the exposure: needlestick injury $\mathrm{n}=37$; cuts $-\mathrm{n}=4$; spattering $-\mathrm{n}=4$.

Immune status of the CMS prior to exposure: with complete immune prophylaxis against HBV $-\mathrm{n}=31$; non-immunized against HBV $\mathrm{n}=14$.

Immune status of the sources (patients): Undetermined - $\mathrm{n}=34$; Determined - 5; HCV $(+)-\mathrm{n}=5$; HBsAg $(+)-\mathrm{n}=1$.

Summary and analysis of the epidemiological information:

Most affected CMS was from the high-risk hospital wards - Emergency and Surgery wards, AICU, Clinical Laboratory $-80.0 \%$ $(n=36)$.

The AUT-HHW is also a hospital section with increased occupational risk due to the nature of the work and the encounter with the incorrect practices in the packing and transport of hazardous hospital waste from the other wards of the MHAT.

The needlestick injury is the most common exposure $-\mathrm{n}=37(82.22 \%)$ of all and is estimated as an incident with the highest risk - 4-fold contagious risk, due to the injury by the hollow-bore needle.

There was one registered case of severe transdermal injury of the right hand in the course of an emergency surgery procedure that leads to long-time disability of the affected. An incident indicative of the nature of traumatism in the MHAT.

As for the time of the exposure, the higher risk of accidents represents the overnight duty - $n=14$ or $31.1 \%$ of all occupational exposures. There is no significant difference between the number of accidents in the time before noon or at the end of the first day shift. 
The sharp medical objects or needlestick injuries affect mostly the HCWs performing risky procedures: nurses $-37.8 \%$, physicians $-33.3 \%$, laboratory technicians $8.9 \%$ or in total $80.0 \%$ of the injured.

The conditions for the safe work environment of the auxiliary personnel - orderlies and the employees at the AUT-HHW should not be underestimated. A total of 9 occupational injuries $(20 \%)$ occurred during transportation and/or handling of the hazardous hospital waste.

The determination of the immune status of the sources of the exposure has proved to be impossible for most of the patients (34 out of $45)$, due to unauthorized consent or leaving the hospital. Thus, they were identified as undetermined $(75.6 \%)$.

The verified immune status of CMS against HBV showed high titres of anti-HBs $\geq 100$ IU/L and was considered as protective for 31 (68.9\%) of the exposed.

Post-exposure prophylaxis was promptly provided following the national standard requirements and hospital regulations. In all of the exposed the monitoring of the antiHCV, HBsAg, anti - HBs and anti - HIV antibody levels showed negative results and no future dynamics.

All of the non-immunized with anti-hepatitis B vaccine underwent a complete immunisation course with mono-vaccine product - Engerix B (GlaxoSmithKline) in 48 hours from the exposure. After the first month, the primary vaccine response was examined and showed results within the reference values.

Summarized analysis of the presented data shows a constant persistence, on local and national scale, of the problems associated with safety procedures that pose an occupational risk to the HCWs of exposure to blood and blood products. Notable is the limited number of documented and controlled exposures in the MHAT, problem persistent in the other hospitals as well. One American multicentre study in the period 2006-2007 indicated that approximately $16 \%$ of the risk exposures with patient's blood remain unreported (Makary et al., 2007). In another study $28.7 \%$ of medical stuff reported injuries in work, 50.4\% did not report and 20.9\% reported sporadically (Wicker et al., 2008). The limited number of documented exposures raises questions about the structure of the professional organization within the microsystem - ward/clinic and the possible negative effect on the HCWs that are directly performing the risky procedures. Crucial role for the limiting of the occupational risk is the human factor - the medical professionals themselves. They are often hindered by influences outside their control - work stress, the necessity to divert attention, fatigue, lack of motivation or use of unsafe medical devices. That is why the systems for reporting and control of the specific medical establishment need to be focused on and to follow a well-structured organizational and practical program to ensure at any time the security of the risky medical procedures and the safety of the staff. Upbringing of a "safety culture" in the medical professionals, through appropriate training programs in the work place, would reduce the likelihood of injuries related to sharp and cutting objects. By using of universal precautions measures such as secured sharp and cutting appliances, elimination of necessity to put cups back on needles and proper use of the equipment, hazardous exposures could be reduced to $80 \%$ (Centers for Disease Control and Prevention, 1997; Jagger, 1996). Several hospitals in California are reporting significant financial savings, about \$ 100 million yearly, after introducing secure medical supplies which 
extinct the necessity for testing for transmission of blood-borne pathogens (American Nurses Association, 1998).

The injuries in the medical practice are a reality, which will remain in the future as well. They however, can be reduced by using safety devices and improving the workflow in a manner of reducing the direct risk of using sharp medical devices. Training for proper handling of such devices, and initiation of the safety procedures is a key component that must be present in the official programs at local and national level. Another useful tool is the periodic analysis of the causes of the incidents in order to identify the factors and prerequisites for risk exposures.

The general strategy for prevention of sharp and needle-stick injuries needs a comprehensive, multidisciplinary approach and prioritization involving all participants manufacturers and users. The coordinated efforts will achieve a real reduction in the incidence of preventable injuries to the HCWs. Reporting of the risky exposures at every medical establishment should become a day-to-day and conscious necessity, part of a general organizational scheme that defines the main steps for action, post-exposure prophylaxis and safety of the medical procedures.

\section{References}

American Nurses Association, Nursing Facts: Needlestick Injury, 1998.

Beltrami, EM, Williams, JT, Shapiro, CN et al., Risk and management of bloodborne infections in health care workers. Clin. Microbiol. Rev., 2000 13(3): 385 $-407$.

Centers for Disease Control and Prevention. Evaluation of Safety Devices for Preventing Percutaneous Injuries among Healthcare Workers during Phlebotomy
Procedures-Minneapolis-St. Paul, New York City, and San Francisco. MMWR. 1997; 46: 21-23.

Europäische Agentur für Sicherheit and Gesundheitsschutz am Arbeitsplatz (OSHA-EU): Vermeidung von Verletzungen durch scharfe/spitze Instrumente am Arbeitsplatz. http://osha.europa.eu/de/sector/healthcar e/prevention-sharp-injuries-workplace. Last accessed on 30 April 2018.

Himmelreich H, Rabenau HF, Rindermann M, Stephan C, Bickel M, Marzi I, Wicker S. The Management of Needlestick Injuries, Dtsch. Arztebl. Int., 2013; 110(5): 61-7;

Himmelreich H, Sarrazin C, Stephan C, Rabenau HF, Marzi I, Wicker S: Frühzeitige Diagnose einer Hepatitis CÜbertragung nach Nadelstichverletzung. Der Unfallchirurg, Epub ahead of print: 8 September 2012.

Jagger J. Reducing occupational exposure to bloodborne pathogens: where do we stand a decade later? Inf Control Hosp Epidemiol. 1996; 17: 573-5.

Makary MA, Al-Attar A, Holzmueller CG, et al.,: Needlestick injuries among surgeons in training. $\mathrm{N}$ Engl $\mathrm{J}$ Med 2007; 356: 2693-9.

Manchikanti, L, Falco, FJ, Benyamin, RM. et al., Assessment of infection control practices for interventional techniques: a best evidence synthesis of safe injection practices and use of singledose medication vials. Pain. Physician, 2012, Sep.-Oct.; 15(5): E573 - 614.

Order № RD 09-70-A, 25.08.2004, Official Bulletin of Ministry of Health 2005, 9: 3-27 [in Bulgarian]

Ordinance № 3 / 08.05.2013. Medical standard for prevention and control of nosocomial infections. Ministry of Health. State Gazette, 2013; 43,131 pp [in Bulgarian] 
Ordinance № 4 / 14.10.2002 for the protection of workers from the risks related to exposure to biological agents at work. Ministry of Health. State Gazette, 2002; 105: 28pp [in Bulgarian]

Prüss- Üstün A, Rapiti E, Hutin Y. Estimation of the global burden of disease attributable to contaminated sharps injuries among health- care workers. Am. J. Ind. Med., 2005, 48: 482-490. doi:10.1002/ajim.20230

Ridzon R, Gallagher K, Ciesielski C, et al.,: Simultaneous transmission of human immunodeficiency virus and hepatitis $\mathrm{C}$ virus from a needle-stick injury. $\mathrm{N}$ Engl J Med 1997; 336: 919-22. CrossRef MEDLINE

Upjohn LM, Stuart RL, Korman TM, Woolley IJ. New HIV diagnosis after occupational exposure screening: the importance of reporting needlestick injuries. Intern Med J 2012; 42: 202-4.
Voide C, Darling KEA, Kenfak-Foguena A, Erad V, Cavassini M, Lazor-Blanchet C. Underreporting of needlestick and sharps injuries among healthcare workers in a Swiss university hospital. Swiss Med Wkly, 2012; 142: w13523.

WHO, Fact Sheet №231 Injection safety: Misuse and overuse of injection worldwide, <www.who.int/ injection_ safety/about/resources.

Wicker S, Cinatl J, Berger A, Doerr HW, Gottschalk R, Rabenau HF. Determination of risk of infection with bloodborne pathogen following a needlestick injury in hospital workers. Ann Occup Hyg, 2008; 52: 615-22.

Wicker S, Jung J, Allwinn R, Gottschalk R, Rabenau HF. Prevalence and prevention of needlestick injuries among health care workers in a German university hospital. Int Arch Occup Environ Health. 2008 Jan; 81(3): 347-54. Epub 2007 Jul 10.

\section{How to cite this article:}

Kircheva, A., R. Konstantinov, K. Stoyanova and Ivanova, E. 2018. Occupational Risk of Sharp Objects or Needlestick Injuries in Medical Practice. Int.J.Curr.Microbiol.App.Sci. 7(06): 793-798. doi: https://doi.org/10.20546/ijcmas.2018.706.092 